\title{
Qualitative evaluation of atmospheric exposure to chemical agents in a workstation of a research laboratory
}

\author{
C.S. Castillo ${ }^{1,2}$, S. Bragança ${ }^{2}$, A. Fernandes ${ }^{2}$, I.F. Loureiro ${ }^{2} \&$ N. Costa ${ }^{2}$ \\ ${ }^{1}$ Sponsored by $\mathrm{CNP} q-$ Brazil \\ ${ }^{2}$ Research Centre for Industrial and Technology Management, School of Engineering of the University of \\ Minho, Guimarães, Portugal
}

\begin{abstract}
A workstation of a research laboratory was analyzed in order to identify the presence of chemical agents in the work environment. For this purpose, colorimetric tubes were used in three of the nine macro activities of the most exposed worker were studied. This study assumed the impossibility of: (i) changing the technical specifications of the linear length of the product X; and (ii) replacing the harmful release agents, resins and solvents by other more innocuous. After being detected the presence of toluene, methanol, $n$-hexane and benzene, the following sequence of improvements were proposed: $\left(1^{\text {st }}\right)$ moving the machine $\mathrm{X}$ to the entries C1-086 and C1-087 on the plant, considering the possibility to eliminate the division between those spaces; $\left(2^{\text {nd }}\right)$ install exhaust ventilation to do the correct atmospheric suction of the air / gases exposed; and $\left(3^{\text {rd }}\right)$ using a proper respiratory mask and special gloves to prevent the contamination.
\end{abstract}

\section{INTRODUCTION}

Regarding a critical exposure of individuals to chemical agents in a workstation in a research laboratory, it was suggested that a qualitative analysis was made in order to identify the type of chemicals. The exposure is related to nine macro activities of a process X (Miranda, L. \& Araújo, F. 2013, Patinha, S. et al. 2013). This process has shown to be the most critical in terms of exposure to chemical agents in the production process (in the machine $\mathrm{X}$ ) of a batch of product X (about 9 linear meters in horizontal position for subsequent cutting into predetermined segments).

Regarding the chemicals that were used on the process $\mathrm{X}$, three of the nine macro activities were considered to be the most critical (the macro activities 1,2 and 9). To perform these three macro activities the following products are used: (1) mold release agent; (2) air-curing resin; and (9) resin used in the process, added to a cleaning solvent.

The main objectives of this work were: (i) identify the individuals that were exposed to chemical agents in the environment of the process $\mathrm{X}$; (ii) characterize the areas were the proceed $\mathrm{X}$ is performed; and (iii) identify the possibility of existence of chemical agents in the laboratory environment.

\section{THEORETICAL BACKGROUND: DOSAGE ABSORBED BY THE HUMAN BODY}

The quantities that constitute the Dosage (D) model (Eq. 1) are: $\mathrm{D}=$ Dosage absorbed by the human body (the amount of contaminant that an organism absorbs in a given time and that can cause damage); $\mathrm{T}=$ Time of exposure to the identified chemical agent; and $\mathrm{C}=$ Concentration of the chemical agent in the area of the selected workplace (Miguel, A.S. 2012, Parsons, K. 2000).

$\mathrm{D}\left[\right.$ year $\left.\times \mathrm{mg} \times \mathrm{m}^{-3}\right]=\mathrm{T}[$ year $] \times \mathrm{C}\left[\mathrm{mg} \times \mathrm{m}^{-3}\right]$

Response: effect caused in the body due to exposure to the toxic agent. Dose / response: relationship between the dose intensity and the proportion of individuals who have a particular effect (or intensity of effect), where the dose / response curve reflects the variations between individuals of the same population. The absorption considered in the study is made by inhalation, therefore the parameter $\mathrm{LC}_{50}$ is used to evaluate the toxicity of a substance (representing the unique value of a substance capable of causing death in $50[\%]$ of tested animals). The lower the $\mathrm{LC}_{50}$, the more toxic will be the substance (Miguel, A.S. 2012, Parsons, K. 2000).

Dimensional analysis consistent with the units of the International System (IS) (ISO / IEC 2008), where the unit 'nd' means non-dimensional.

$\mathrm{D}\left[\mathrm{s} \times \mathrm{kg} \times \mathrm{m}^{-3}\right]=\mathrm{T}[\mathrm{s}] \times \mathrm{C}\left[\mathrm{kg} \times \mathrm{m}^{-3}\right]$

$\times 31.54[\mathrm{nd}]$ 
The sensitivity coefficients of the Dosage (D) model (Eq. 2) as a function of [s], [kg] and [m]. These variables can be modified to minimize the sensitivity coefficients of the Dosage (D) quantity in the Equation 2 (ISO / IEC 2008).

$\frac{\partial D}{\partial[s]}=[k g] \times\left[m^{-3}\right] \times 31,54[n d]$

$\frac{\partial D}{\partial[k g]}=[s] \times\left[m^{-3}\right] \times 31,54[n d]$

$\frac{\partial D}{\partial[m]}=[s] \times[k g] \times\left[m^{-4}\right] \times-94,61[n d]$

\section{METHODOLOGY}

The methodology used in this study was divided into two parts.

\subsection{Identification of people directly / indirectly} exposed and characterization of the laboratory area that circumscribes the process $X$, regarding the atmospheric exposure to chemical agents during the three most critical macro activities

Checklists were developed and applied (Loureiro, I.F. 2013), and direct observation and site visits were made to assist in the analysis of the characterization. The layout of the research laboratory is included in Figure 1. The process $\mathrm{X}$ is located in the section of the plant identified by the code C1-084.

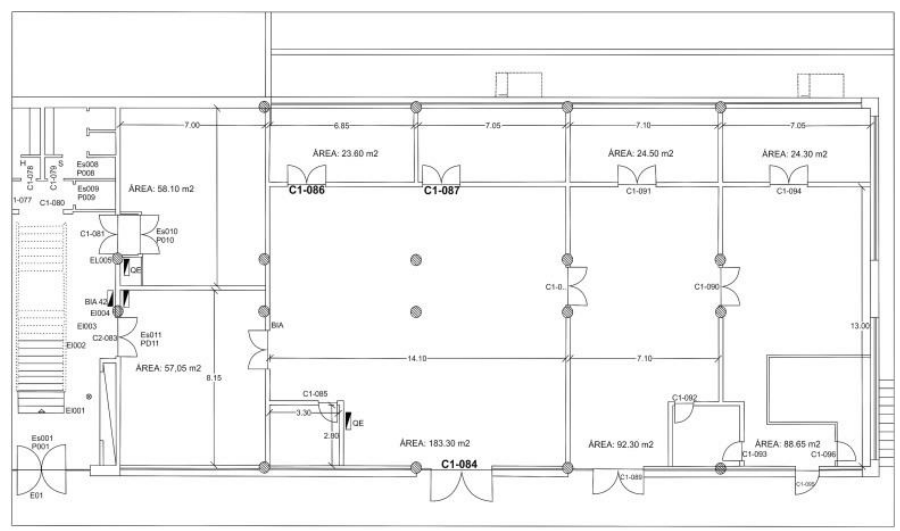

Figure 1. Layout of the research laboratory.

\subsection{Identification of the possibility of the existence} of atmospheric chemical agents during the activities developed in the area of process $X$, which uses more critically chemical agents during three specific macro activities

The methodology used to collect samples of the concentrations of chemical agents was (Miguel, A.S. 2012, Parsons, K. 2000):

Measurement Method: Colorimetric indication with active sampling of chemical agents by direct reading (punctual and short duration reactive tubes) and passive sampling (tube by diffusion or long duration).

Major quantities to be measured: Concentration (C) of the chemical agent (previously identified) in [ppm] and Dosage (D) in [ppm $\times \mathrm{h}]$. However, this direct reading does not enable a very reliable indication of the exact values of (C) and (D), only the identification of the possible existence of chemical agents in the atmosphere where the worker selected in the study is most critically exposed.

Measuring Equipment: The reaction occurred between the chemical agents present in the environment analyzed and the chemical product inside the tubes can be detected by colorimetric change occurred in the detector of colorimetric tubes. A Dräger pump was used to collect the air present in the environment, in the region closest to the most exposed worker's airways. After the test, the colorimetric tube was broke rendering it useless for future measurements. In each test a thermo-anemometer was used to measure temperature $\left[{ }^{\circ} \mathrm{C}\right]$ and air velocity $\left[\mathrm{m} \times \mathrm{s}^{-1}\right]$. Besides being registered the exposure time (and measurement time) for each of the 3 most critical macro activities, it was also considered 1 pseudo activity without exposure to chemical agents.

Sampling strategies: Despite the identification of persons exposed of the workplace, due to time constraints, it was not performed a student sampling. The study was based on the complaints of the most exposed worker, estimating, in this way, the necessary protection to other people who also attend the workplace. Initially, the safety sheets provided were used for the preliminary analysis of the eight chemical products used in the research laboratory ( 1 external mold release agent, 1 cleaning liquid $X, 1$ cleaning liquid $\mathrm{Y}, 1$ epoxy resin, 1 polyester resin iso for infusions, 1 vinylester resin $\mathrm{X}, 1$ vinylester resin $\mathrm{Y}$ and 1 sealant), which helped in choosing the colorimetric tubes available that would most likely react with the chemical agents present in the atmosphere in which the selected worker is located during the course of the three most critical macro activities. The individual air samples were collected, at a particular time, in relation to the reactive tubes for punctual measuring and short duration, representing the conditions at the time of collection, except for the long-term sampling or for the diffusion of the ammonia (which the duration of the measurement lasted 2 hours). Of the many available colorimetric tubes, only 5 were selected ( 1 tube for instantaneous measuring / toluene; 1 tube of short duration / benzene; 1 tube of short duration / methanol; 1 tube of short duration / n-hexane; and 1 diffusion colorimetric tube for detection of the ammonia, in which a device for fixation of the respective tube was used to ensure greater proximity to the respiratory system of the most exposed worker during a measurement pe- 
riod of 2 hours). The selection criteria for the colorimetric tubes, allocated according to the available safety sheets, emphasized 2 specifications of the chemical products: (i) the composition; and (ii) its toxicity. The detection started with the colorimetric tubes at the lower possible concentrations, eliminating unnecessary testing for higher concentrations.

\section{RESULTS AND DISCUSSION}

The value of current atmospheric pressure $[\mathrm{hPa}]$ used in Table 1 was collected on the day of the sample collection $(06 / 14 / 2013,12 \mathrm{~h}: 00 \mathrm{~min}$ to 14h:00min) in (IPMA 2013). The main results are presented in Table 1. The data of 'Measurement range' column on the Table 1 were extracted from Dräger technical manuals of the colorimetric tubes used in these study.

Table 1. Key variables for identifying the presence of chemical agents in the atmosphere of the three most critical macro activities of the process $\mathrm{X}$ of workstation.

\begin{tabular}{|c|c|c|c|c|c|}
\hline \multirow{2}{*}{$\begin{array}{l}\text { most } \\
\text { critical } \\
\text { macro } \\
\text { activities }\end{array}$} & \multicolumn{5}{|c|}{$\begin{array}{l}\text { Variables of interest to identify the possibility of existence of chemical agents in the } \\
\text { atmosphere of the most critical macro activities of the process X, considering the most } \\
\text { exposed worker in an environment with closed windows/doors } \\
\text { (exhaustion and ventilation systems off) }\end{array}$} \\
\hline & $\begin{array}{l}\text { Chemical } \\
\text { agent }\end{array}$ & $\begin{array}{l}\text { Correction } \\
\text { factor of } \\
\text { atmospheric } \\
\text { pressure* } \\
\text { [nd] }\end{array}$ & $\begin{array}{l}\text { Measurement } \\
\text { range } \\
{[\mathrm{ppm}]}\end{array}$ & $\begin{array}{l}\text { Colorimetric variation on } \\
\text { the reactive tube } \\
\text { [presence } \mathrm{X} \text { absence] }\end{array}$ & $\begin{array}{l}\text { Exposure time } \\
\text { [minutes] }\end{array}$ \\
\hline (1) & $\begin{array}{l}\text { Toluene } \\
\text { Methanol } \\
\text { n-hexane } \\
\text { Benzene }\end{array}$ & 0.84 & $\begin{array}{c}50-400 \\
50-3000 \\
50-1500 \\
0.5-10\end{array}$ & $\begin{array}{l}\text { absence } \\
\text { presence } \\
\text { presence } \\
\text { presence }\end{array}$ & 10 \\
\hline (2) & $\begin{array}{l}\text { Toluene } \\
\text { Methanol } \\
\text { n-hexane } \\
\text { Benzene }\end{array}$ & 0.84 & $\begin{array}{c}50-400 \\
50-3000 \\
50-1500 \\
0.5-10\end{array}$ & $\begin{array}{l}\text { presence } \\
\text { presence } \\
\text { presence } \\
\text { presence }\end{array}$ & 15 \\
\hline (9) & $\begin{array}{l}\text { Toluene } \\
\text { Methanol } \\
\text { n-hexane } \\
\text { Benzene }\end{array}$ & 0.84 & $\begin{array}{c}50-400 \\
50-3000 \\
50-1500 \\
0.5-10 \\
\end{array}$ & $\begin{array}{l}\text { presence } \\
\text { presence } \\
\text { presence } \\
\text { presence }\end{array}$ & 15 \\
\hline $\begin{array}{l}(1)+(2) \\
+(9)+ \\
\text { (pseudo } \\
\text { activity) }\end{array}$ & Ammoniac & 0.84 & $\begin{array}{c}10-750 \\
\text { (considering two } \\
\text { hours of } \\
\text { measurement) }\end{array}$ & absence & 120 \\
\hline
\end{tabular}

A more conservative measure, aiming to protect people less exposed was done to minimize the effects of absorption of chemical agents. As reference, it was adopted the most exposed worker. However, it should be taken into account the toxicological effects related to the exposure to chemical agents, especially those with higher levels of Concentration (C) and Time of exposure (T), when compared with their respective Exposure Limit Values (ELV's) WA (Weighted Average) / ST (Short Term) / MC (Maximum Concentration) (Miguel, A.S. 2012, NP-1796 2007, Parsons, K. 2000).

By increasing the dose (or, the larger the inclination of the line of the dose / response relationships; considering the $\mathrm{X}$ axis as the log dose $\left[\mathrm{mg} \times \mathrm{kg}^{-1}\right]$ and the $\mathrm{Y}$ axis as the response [\%]), the normal thing to happen is that it will also increase the number of affected individuals in the exposed population - being able to predict the danger of toxic substances. Thus, the faster this absorption tends to occur, and more quickly the adverse toxicological effects of the chemical agents begin. Furthermore, to maintain (D) constant it is needed to balance the relationship between $(\mathrm{T})$ and $(\mathrm{C})$, that is, the higher the value of $(\mathrm{T})$, the lower will be the value of $(\mathrm{C})$ or vice versa. Where the scaling of the weighting of values to be assigned to the variables (T) and (C) aims at minimizing the value of (D) below the maximum acceptable levels in the relevant legislation, e.g. the (ELV), by considering the most population with a specific occupational exposure to chemical agents in the atmosphere for 8 hours per day / 40 hours per week (Miguel, A.S. 2012, NP-1796 2007, Parsons, K. 2000).

In the Equations 3-5 the length quantity in [m] represents one of the dimensions that constitute the volume quantity in $\left[\mathrm{m}^{3}\right]$, where the mass quantity [kg] of the chemical agent (previously identified) is deposited, so [m] is inversely proportional to the Concentration (C), considering [kg] constant (ISO / IEC 2008).

To facilitate the analysis of proposals for improvement, it was attributed certain actions in accordance with the need to prioritize their adoption. Furthermore, the priority routes as to minimize the effects of the chemical agents are: $\left(1^{\text {st }}\right)$ Respiratory; $\left(2^{\text {nd }}\right)$ Cutaneous; and $\left(3^{\text {rd }}\right)$ Digestive. So, for the value of Dosage (D) absorbed by the most exposed worker's body to chemical agents in the workplace is minimized, were presented suggestions on how the main variables (T) and (C) can contribute to the maximization of the response time (or minimization of sensitivity) of the Equation 1 (hence minimizing the inherent toxicological effects). In general, the variables that affect the increase of the response time of the Dosage (D) model (Eqs 1-2) are (Miguel, A.S. 2012, Parsons, K. 2000):

- $\left(1^{\text {st }}\right)$ Engineering measures: Isolation of the mass of the chemical agent in exposure (which complicates the accessibility to the production system); Mechanical exhaustion (higher cost associated); Ventilation of the mass of the chemical agent to the outside of the atmosphere in exposure (higher cost associated and difficulty of dimensioning if there is need for air conditioning for the productive environment); Cure / polymerization speed of the chemical agents to the air and / or to the temperature (higher cost associated and complexity in the dimensioning of the technical specifications / performance of the polymerized rope and of the respective productive parameters).

- $\left(2^{\text {nd }}\right)$ Organizational measures: Amendment to the working hours of the workforce (higher cost associated and difficulty with the training and harmonization of working hours). 
- $\left(3^{\text {rd }}\right)$ Measures related to the adoption of personal protective equipment: Use of Personal Protective Equipment (higher cost associated and discomfort). Indications for priority usage: $\left(1^{\text {st }}\right)$ Filter suitable for inhalation; and $\left(2^{\text {nd }}\right)$ Special gloves for cutaneous, depending on the analysis of the safety sheets of the chemical products used, both exhibiting specificity in relation to the need for effective protection to chemicals in exposure.

It were listed in brackets the main limitations inherent to the direct adoption of the respective measures, e.g. were not included the effects of amortization of investments associated with them.

There are also other variables not included in the Dosage (D) model (Eqs 1-2) that influence the response time of the Dosage (D) quantity: susceptibility of certain human beings who have different settings in terms of metabolism $\left[\mathrm{W} \times \mathrm{m}^{-2}\right]$, health status, emotional state / trait, genetic predisposition, respiratory capacity and surface area of their bodies (Miguel, A.S. 2012, Parsons, K. 2000).

\section{CONCLUSION}

The greater the synergy between measures of engineering, of work organization and those related to the adoption of personal protective equipment, the greater tends to be the complexity in reconciling simultaneity their advantages and disadvantages.

After detecting the atmospheric presence of toluene (except in the first macro activity), methanol, nhexane and benzene in the workplace; they were proposed primarily three changes for improvement in the following sequence: $\left(1^{\mathrm{st}}\right)$ displacement of the machine $\mathrm{X}$ to plant spaces whose inputs are C1-086 and C1-087, containing about 13.90 meters (greater than the 9 meters in length required for producing the product $\mathrm{X}$ ), considering the possibility of eliminating the partition between those spaces; $\left(2^{\text {nd }}\right)$ installation of exhaustion fans dimensioned for the atmospheric suction of air / gases; and $\left(3^{\text {rd }}\right)$ according to Miguel, A.S. (2012), Parsons, K. (2000), usage of proper respiratory mask and special gloves for isolation of the cutaneous route.

Where there was variation in color in the colorimetric tube, as a function of direct atmospheric exposure to the chemical agents, it is recommended to make a collection and subsequent analysis in an accredited laboratory by determining the reliable concentration of gases and vapors. In cases where there was no colorimetric change in the reactive tube, it is recommended to use other colorimetric tubes for detection of eventual unidentified chemical agents in the atmosphere of this study, and in the assumption of detection, to adopt the same procedure described above (ISO / IEC 2008). Not always the individual samples can be used as representative of the degree of contamination of the environment under investigation, unless the source of contamination of the study is stable (Miguel, A.S. 2012, Parsons, K. 2000, Montgomery, D.C. 1991).

\section{REFERENCES}

Instituto Português do Mar e da Terra (IPMA) 2013. Current Atmospheric Pressure $(h \mathrm{~Pa})$. Available in: <http://www.ipma.pt/pt/otempo/obs.superficie.mapa/>. Accessed: 14 jun. 2013.

ISO / IEC 2008. Guide 98-3. Uncertainty of measurement: Guide to the Expression of Uncertainty in Measurement (GUM: 1995).

Loureiro, I.F. 2013. 'Protocolo de higiene industrial: avaliação da exposição a agentes químicos'. 'Material de Apoio à Unidade Curricular de Higiene Industrial do Mestrado em Engenharia Humana, Universidade do Minho'.

Miguel, A.S. 2012. 'Manual de higiene e segurança do trabalho'. 12 (ed.). 'Porto Editora'.

Miranda, L. \& Araújo, F. 2013. Fibrenamics. Available in: <http://www.fibrenamics.com/>. Accessed: 6 jun. 2013.

Montgomery, D.C. 1991. Introduction to statistical quality control. 2 (ed.). New York: John Wiley \& Sons.

NP-1796 2007. 'Segurança e saúde no trabalho. Valores limite de exposição profissional a agentes químicos'. Available in: <http://www.ipq.pt/backFiles/prNP001796_2007.pdf>. Accessed: 24 mai. 2013.

Parsons, K. 2000. Environmental ergonomics: a review of principles, methods and models. Applied Ergonomics, 31(6): 581-594.

Patinha, S., Vyhnalek, M., Alves, A., Cunha, F., Rana, S. \& Fangueiro, R. 2013. Production process of Braided Composite Rods (BCR). Presented in: 'Materiais 2013', 25-27 June 2013, Coimbra, Portugal. 